\title{
O Combate Subtrativo: A Espiritualidade do Esvaziamento como Norte da Filosofia Corporal no Karate-Do
}

\author{
The Subtractive Fight: The Spirituality of the Empty Hands Method as the North \\ of the Body Philosophy in Karate-Do
}

\author{
Cristiano Roque Antunes Barreira* \& Marina Massimi \\ Universidade de São Paulo
}

\begin{abstract}
Resumo
O karate é uma técnica de combate sem armas que, sustentada por uma antiga tradição, tem como seu principal objetivo a formação do caráter do praticante. A compreensão da visão de mundo na qual o karate nasceu e se desenvolveu é debitária de uma dinâmica espiritual e psicológica singular cujo conhecimento é imprescindível para apreendê-la. O objetivo desta pesquisa é analisar o karate por meio de sua espiritualidade, já que, junto aos textos fundamentais de sua tradição recente, ela é tida como a essência presente em todas as dimensões da expressão da arte. Para tanto, vale-se de uma metodologia historiográfica de perspectiva fenomenológica. $\mathrm{Ka}$ rate-do veicula a espiritualidade do esvaziamento como norte de sua filosofia corporal. Temas com linhas fronteiriças tênues entre si são analisados pela perspectiva de tal espiritualidade. A abrangência desta dinâmica corresponde a um combate subtrativo visando uma apreensão fluida e intutitiva da realidade.

Palavras-chave: Karate; espiritualidade; história das idéias psicológicas; corpo; esporte.
\end{abstract}

\begin{abstract}
Karate is a fight practice that does not make use of weapons. It is based on old traditions and its main aim is to develop a sense of personality in the practitioner. Karate originated from unique spiritual and psychological dynamics, which are of utmost importance for the full understanding of this practice. The objective of this research is to analyze karate-do by means of its spirituality. This is because, together with the fundamental texts about the recent tradition of this fight, spirituality is considered to be the essence present in all dimensions of the artistic expression of karate. To this end, the historiographical methodology of phenomenological perspective was employed in this study. Karate-do has the spirituality of the empty hands method as the north of its body philosophy. Themes with blurred borders are analyzed from this spiritual point of view herein. This dynamics includes the subtractive fight, aiming at the fluid and intuitive understanding of reality.

Keywords: Karate; spirituality; history of psychological ideas; body; sport.
\end{abstract}

Sistematizar a percepção formativa e educativa do karate tem sido uma das maiores adversidades encontradas pela comunidade carateísta que conta com centenas de milhares de praticantes federados no Brasil. Nesse sentido, esta pesquisa vem conjugar esforços para realizar o resgate e a interpretação daquelas experiências que constituem o karate.

A opção por investigar a espiritualidade da arte corresponde justamente a uma tentativa de aproximação desta constituição. Antes de ser mais um dos representantes do esporte moderno, o karate pode ser mais bem entendido como uma prática de caráter ritual, destinada contemporaneamente à preparação para combates e ao desenvolvimento espiritual. É assim, por exemplo, que Gichin Funakoshi (1868-1957), considerado o pai do karate moderno, define tecnicamente a arte das mãos (te) vazias (kara), atribuindo às mãos uma determinação de técnica

* Endereço para correspondência: Rua Arlindo Béttio, 1000 São Paulo, SP, 03838-000. Tel.: Fax (EACH-USP): (11) 6541 1635.E-mail: crisroba@usp.br. Apoio.PRP-USP/FAPESP. de combate que não faz uso de armas, por isso vazia. Funakoshi insistiu em veicular a experiência de sua tradição, que tanto ele como muitos de seus contemporâneos e ascendentes faziam, como um caminho atribuindo definitivamente ao karate o posposto do, enfatizando os aspectos morais e espirituais da arte (1975/1994, 1935/1997, 1988/1998). Para ele, tratava-se menos de formar combatentes, do que de formar o caráter dos praticantes. E esta formação tinha uma orientação definida e presente já na denominação daquela tradição, karate-do ou o caminho em que através da técnica se alcança o vazio. Funakoshi é conhecido como o pai do karate moderno por tê-lo levado do arquipélago de Okinawa apresentando-o ao restante do Japão e ter dedicado sua vida a seu desenvolvimento, tornado-se o maior representante de sua arte. Suas atividades como professor de karate incentivaram outros mestres a difundirem a arte de Okinawa, mas talvez, em contraste com outras autoridades no mundo do karate, sejam seus escritos que, por sua qualidade e fidelidade descritiva, mais contribuam para o reconhecimento do karate como prática de impacto transcultural. 
A herança deixada por Funakoshi foi difundida mundialmente, sobretudo, pela atividade de Masatoshi Nakayama (1913-1987), o mais conhecido entre seus discípulos que liderou uma das organizações mais efetivas no que diz respeito à diáspora mundial do karate. Por esta razão, o conhecimento de como o karate shotokan pode ser compreendido no Ocidente passa, necessariamente, pela voz e pela redação de Nakayama, autor de inúmeros livros técnicos sobre a prática.

\section{Objetivos}

O objetivo desta pesquisa é analisar as idéias psicológicas centrais do caminho do karate presentes nos escritos de Masatoshi Nakayama a partir da espiritualidade que as penetra e que fora inicialmente veiculada por Funakoshi. Os referenciais desta espiritualidade estão baseados no pensamento que a contextualiza e, finalmente, que a precede, possibilitando o alcance daqueles estratos motivacionais profundos que, segundo os textos da tradição, encerrariam sua essência.

\section{Método}

Esta pesquisa segue apontamentos próprios dos métodos historiográficos que têm sido utilizados para investigar a história da psicologia e, mais especificamente, a história das idéias psicológicas (Massimi, 1998; Massimi, Campos \& Brozek, 1996). O método historiográfico insiste sobre uma atenção à demanda do objeto investigado. Assim, caso se adote, previamente à aproximação do próprio objeto em questão, uma abordagem metodológica pré-concebida, incorre-se na pretensão de que as possibilidades de interpretação sejam reincidentes, estavelmente repetitivas, quando não o são. Cada história é particularmente situada em suas fontes e possibilidades de aproximação. Situá-las, portanto, e situar as condições de leitura para que a interpretação das concepções seja o mais próxima possível da compreensão compartilhada naquele tempo e espaço definidos, torna-se um dos principais cuidados metodológicos ${ }^{1}$. A aproximação historiográfica ao objeto, portanto, é uma aproximação fenomenológica que busca se esquivar de anacronismos (presentes em um programa de pesquisa rígido previamente definido, por exemplo) e relativismos (presentes no princípio de que as estruturas definidoras de outras culturas e tempos são inapreensíveis), procurando, para dizer com Husserl (2002), entrever a conexão histórica do interior e "revivificar a concepção sedimentada" (p.100).

\section{Resultados}

Os resultados estão elencados em quatro etapas que têm como fio condutor o que se compreende ser a espiritualidade do esvaziamento. A espiritualidade vem considerada neste trabalho em seu sentido largo, ou seja, como sentido que se endereça à qualidade de dimensão espiritual que, por sua vez, na corrente fenomenológica clássica, "implica a possibilidade estrutural de abertura para o outro, para as coisas e para si mesmo, num processo de apreensão da realidade que remete à presença da razão" (Coelho Júnior \& Mahfoud, 2006, p. 13). Assim, deve-se entender a espiritualidade como possivelmente menos ou mais associada a tradições religiosas, com graduações e de-gradações que dirão respeito tanto à objetividade do ambiente cultural quanto à subjetividade do ambiente interpessoal ou comunitário. O esvaziamento conduz esta espiritualidade, que será desdobrada ao longo do texto, incidindo e dando unidade a domínios diferentes, embora com linhas fronteiriças tênues entre si, da dinâmica humana envolvida na prática do karate. São eles: a aprendizagem, a moral, o psiquismo e, finalmente, o combate.

\section{Esvaziamento e Aprendizagem}

Ao defender que o karate deve restringir-se ao estudo de técnicas de luta sem armas - em contraponto às críticas que argumentavam ser esta uma prática que empobrecia a variedade de conhecimentos das artes marciais - Nakayama afirma que:

há simplesmente pouco tempo em nossa vida para nos tornarmos mestres em um grande número de armas ou sistemas ou diferentes artes. É possível trabalhar bem em um grande número de diferentes coisas, mas impossível tornar-se mestre em todas elas. Nós nos concentramos nas técnicas do karate-do e tentamos verdadeiramente nos tornarmos mestre delas. (1983, p. 66)

As concepções de aprendizagem e maestria que estão ali pressupostos pesam sobre esta afirmação dando-lhes seu sentido. Tal concepção não difere da encontrada na obra de Gichin Funakoshi, de onde se destacam dois pontos principais. O primeiro deles considera que, tendo como ponto de partida um elemento técnico, sobre o qual se dedicou próprios textos de Funakoshi e Nakayama dão o tom da exigência de simplicidade de leitura ancorada nestas experiências, em geral, esquivas às especulações filosóficas eventualmente presentes na redação de Suzuki. Os aspectos de base do mundo sino-aculturado, ao qual pertence o Japão, que possam contribuir para compreender tendências precedentes e subentendidas em eventuais conteúdos estão referenciados em Anne Cheng (1997) e sua Histoire de la Pensée Chinoise. Contudo, aquilo que diz mais, no tocante ao objeto investigado, são os próprios textos que versam diretamente a seu respeito. 
verdadeiro empenho para que fosse bem aprendido, podese tomá-lo como modelo de referência, a partir do que facilmente são solucionados outros elementos técnicos. Isso porque os princípios técnicos têm pontos essenciais comuns a quaisquer movimentos do karate. Assim também ocorre com as artes: sendo os princípios comuns a todas, a verdadeira aprendizagem de uma arte leva mais facilmente à aprendizagem de outras artes. Essa noção é comum ao budismo zen que busca, através de cada método que o tem como fundamento, uma essência comum que é o vazio, ou Buda (Herrigel, 1958/1993). O segundo ponto é o de que o verdadeiro aprendizado não se dá pela teoria ou pelas palavras e sim pela experiência viva, conforme categoricamente posto pelo mestre Funakoshi: "Você não pode aprender por meio de palavras. Você precisa aprender com o corpo" (Funakoshi, 1998, p.48). Essa noção ecoa o budismo zen e também ao xintoísmo, que ocasionalmente são considerados como vivências e modos de vida mais propriamente do que como doutrinas (Gardini, 1989). Herrigel reforça esta característica entendendo que os escritos dos Sutras Sagrados, ou textos sobre o Budismo Zen, apenas farão sentido e dirão algo àqueles que já anteriormente tenham de alguma forma experimentado aquilo que, metaforicamente, esteja ali explanado.

Nakayama oferece vários elementos que auxiliam a compreensão metódica do processo de aprendizagem no karate particularmente. O aprendizado do karate moderno foi sistematizado para ser realizado gradualmente, passo a passo, numa ordem de dificuldade crescente na qual, de forma subtrativa, obstáculos esvaecem e são superados, passando-se então a obstáculos de outras naturezas. O aprendizado, sempre gradual, deve enfatizar, inicialmente, os fundamentos e as técnicas básicas permitindo que haja perfeito domínio dos movimentos. A atenção volta-se à expansão e contração muscular, visando o seu controle. Deve-se atentar e aprender conscientemente a controlar os músculos. Mas esse momento também precisa ser superado, a necessidade de atenção consciente para a boa utilização dos músculos deve acabar, isto é, após muita prática, o controle dos músculos é feito sem o recurso de esforços da atenção consciente. Do aprendizado de postura e técnica, passa-se ao aprendizado de táticas e, posteriormente, de estratégias. "Mas isto nos afasta de espontaneidade natural e nossas mentes se fixam em posturas específicas, técnicas e estratégias" (1983, p. 62).

Para esclarecer esse processo, Nakayama cita uma passagem de um texto clássico, atribuído a uma carta do monge zen budista Takuan Soho (1573-1645), destinada ao esgrimista Yagyû Munemori no século XVII. No texto citado por Nakayama, Takuan defende a idéia de que o mestre, após o verdadeiro aprendizado, retorna ao estágio do principiante:

O principiante não sabe como segurar a espada nem como assumir uma posição. Sua mente divaga o tempo todo. Se for atacado, ele reage, mas não tem nenhuma estratégia. Então, à medida que seu corpo aprende a usar técnicas e posturas, ele passa a conhecer os estratagemas da batalha e sua atenção é desviada para várias coisas diferentes. Quando ele tenta golpear, vacila e se atrapalha. Entretanto, depois de meses e anos de treinamento, ele passa a aplicar as técnicas e posturas sem que precise fazer um esforço consciente. Esse é o estágio de principiante. Com desapego, livre de obstáculos, o movimento apropriado torna-se possível. (Takuan, Zenji, Fudôchisin myôroku, apud Nakayama, $1978 / 1998$, p. 22)

Dessa maneira, o que se pretende é que os primeiros estágios da aprendizagem sejam dominados, até se tornarem livres, espontâneos, como que esquecidos, não mais ocupando a consciência - o que caracteriza sua transcendência. Se isso acontece, esses princípios, ao deixarem o estatuto de obstáculos, tornam-se uma prática certa de retidão que liberta a consciência para que ela se ocupe de outros estágios mais avançados até idealmente atingir a libertação plena, isto é, não mais se ocupar. Neste processo, diz-se no budismo zen, "quando as condições estão completamente amadurecidas" (Suzuki, 1936, p. 3) basta uma palavra do mestre para que haja a libertação.

Após a aprendizagem das habilidades técnicas fundamentais, quando não é mais necessária maior atenção sobre as mesmas, o praticante experiente avança para outros estágios da prática e pode lutar. Dentre esses estágios mais avançados de prática, aperfeiçoar-se-ão noções de distância e velocidade, táticas e estratégias. A prática da luta livre (jiyû kumite) finalmente poderá começar como método de aprendizagem. Todos os obstáculos anteriormente superados serão postos à prova e quanto mais desnecessário for que a atenção se volte a qualquer um deles (ocupações mentais com técnica, distância, tática, estratégia), menor a distância do cultivo daquilo que a luta intenta em uma instância mais profunda: o "sexto sentido do ataque e da defesa" (Nakayama, 1978/1998, p. 22), a "verdadeira visão", o estágio mais evoluído de aprendizagem no processo de transcendências. A verdadeira visão só pode ocorrer com o auto-esquecimento, com a liberdade espontânea que o treinamento gradual permite acontecer. Para esclarecer melhor isto, Nakayama ${ }^{2}$ recorre mais uma vez aos textos clássicos fazendo uma citação do esgrimista Yagyû Munemori:

\section{A espada e o Zen são a mesma coisa}

As artes marciais e o Zen concordam em muitos pontos. Ambos, em especial, desprezam e proíbem o apego às coisas materiais. E dão grande importância a isso. Não importa como a pessoa executa as técnicas que praticou em segredo. Se sua mente estiver apegada às técnicas, ela não conseguirá vencer. É fundamental, no treinamento, que a mente não se fixe, quer nos movimentos do adversário, quer no ato de golpear ou de bloquear. (Yagyû Munemori, Heihôka densho, apud Nakayama, 1978/1998, p. 22)

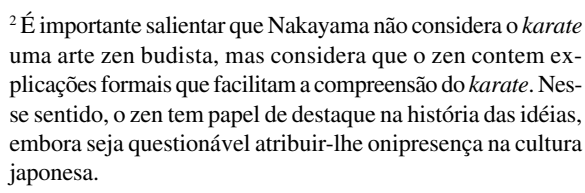

${ }^{2}$ É importante salientar que Nakayama não considera o karate uma arte zen budista, mas considera que o zen contem explicações formais que facilitam a compreensão do karate. Nesse sentido, o zen tem papel de destaque na história das idéias, embora seja questionável atribuir-lhe onipresença na cultura japonesa. 
Uma análise fenomenológica inicial de alguns aspectos deste conteúdo favorece seu esclarecimento, já que busca uma redução à essência, ou seja, busca os elementos estruturais do fenômeno. O alerta de Nakayama a respeito desta dinâmica psíquica aponta para a superação dos obstáculos, o que pode ser interpretado justamente como superação de mediações existentes entre ação e sujeito. Por sujeito compreende-se simplesmente a intencionalidade, isto é, o que numa perspectiva de inspiração fenomenológica clássica, como esta se pretende, é uma estrutura universal, aquilo que Husserl (1992) identifica como caráter apodítico da consciência ou simplesmente sua essência: a consciência é "consciência de" alguma coisa. Esclarecido o uso desta concepção universal de sujeito - enquanto pura intencionalidade que se preenche variadamente em sínteses passivas e ativas, por exemplo, em atos de consciência como recordação, reflexão, projeção, atenção - se reconhece no conteúdo analisado o privilégio dado ao último dos atos mencionados, a atenção perceptiva. Portanto, aquilo que é desejável é a ação sem apegos, estes correspondentes a intermediários mentais, isto é, sem presença atuante de interposições que são entendidas como obstáculos à ação efetiva e plena. Assim, dentre o que é acima tratado por coisas materiais - sem que esta seja uma análise exaustiva das possibilidades de definição de coisas materiais -, podese individuar a atenção reflexiva e, mais especificamente, o pensamento representativo. A representação, como lembra Ales Bello (2003, p. 137), engloba aqueles atos da consciência, tais como a re-figuração e a fantasia, que têm um funcionamento re-produtivo. É sobre estas reproduções e com seu uso que a reflexão pode atuar, daí a individuação específica desta função. Postas como obstáculos, deve-se superá-las - cada qual ao seu modo, o zen e as artes marciais com métodos relativamente diferentes para o alcance da mesma finalidade. Transcende-se gradualmente a necessidade de atenção consciente a tais coisas materiais, bem entendido, não ao que é simplesmente empírico e consciente aos sentidos, mas àquilo que se impõe como mediação mental diante de uma expectativa, de uma tensão. Esta mediação - por exemplo, o apego à técnica, aludido em Munemori - apresenta-se como pretensa solução do impasse combativo e, como tal, a pré-tensão busca garantia prévia, antecipada e, portanto, no passado, a uma tensão que é atual. A ausência destes obstáculos dá acesso ao uso espontâneo do que se tratará como um sexto sentido. Nakayama, discorrendo sobre as idéias de Takuan, afirma que:

. . . se ficar totalmente absorvido em qualquer coisa que prenda a atenção, então a derrota será inevitável. A solução de Takuan para o problema foi que a mente não ficasse em lugar algum - que fique espalhada através de todo o corpo, sem se concentrar em nada em particular. Por aí, ele disse, a mente estará à disposição em qualquer parte em que a situação necessite de imediata atenção. (1983, p. 60)

Observe-se que Nakayama argumenta que a solução de Takuan é um desprendimento de lugar, ou seja, um desprendimento mental quanto ao espaço. Desprendida das localizações, a consciência flui sem localização específica, como indica a última parte da citação, pronta para reagir à necessidade de atenção imediata, o que sugere uma disposição temporal, isto é, pronta para o que vier sem prédeterminar espacialmente o que virá. Se, por si só, o conteúdo expresso deixa algumas dúvidas quanto à especificidade do elemento temporal na afirmação, a segurança para tanto pode ser ganha pela compreensão que Suzuki (1936) tem daquilo que diferencia a atividade filosófica ocidental e oriental. A "manipulação de conceitos" (p. 20) - tais quais as peças estabelecidas que contribuam para a construção filosófica, tipicamente ocidental e espacialmente delimitada - difere do funcionamento filosófico oriental predominante, intuitivo e temporalmente fluido, pronto e atento às mudanças. Esta "filosofia do tempo em oposição à filosofia do espaço" (p. 25) corresponde a esse desprendimento espacial necessário a uma prontidão temporalmente centrada.

Portanto, contrariamente à aprendizagem caracteristicamente ocidental, com sua função analítica calcada na soma conceitual, a aprendizagem do esvaziamento é imersiva e se fundamenta na subtração de mediações.

\section{Esvaziamento e Moral}

A recorrente preocupação de Nakayama com a pressa em se praticar a luta no karate esportivo tem a ver com o salto das etapas fundamentais preliminares à luta (sobre tais etapas veja-se Barreira \& Massimi, 2006). Referindose à última destas etapas, escreve o autor:

Essa etapa preliminar para o jiyû kumite requer grande habilidade, por isso ela não é recomendada para principiantes, cujas técnicas não serão executadas com perfeição e por isso se mostrarão ineficazes. Só o praticante experiente saberá tirar proveito desse método para cultivar a verdadeira visão, o sexto sentido do ataque e da defesa. (Nakayama, 1978/1998, p. 17)

Abre-se à importância do kime, conceito essencial do karate, que é o objetivo de aprendizagem pela prática desde os estágios iniciais. Daí a inquietude de Nakayama quanto aos riscos de que o karate esportivo ocasione a perda da essência da arte. "Ultimamente, a tendência é passar para o jiŷu kumite prematuramente; e o resultado dessa impaciência - kime sem força ou vigor - . . . Essa precipitação é um erro, mas apesar disso, creio que ela está tomando vulto" (Nakayama, 1978/1998, p. 17).

Inquietude, como relembra Nakayama, comum a Funakoshi.

Veja, antes de Mestre Funakoshi morrer, eu comecei a pesquisar a idéia de desenvolver torneios, ou - karate esporte. Mas quando eu perguntei ao Mestre Funakoshi sua opinião, ele se recusou a comentar. Ele estava preocupado, veja você, que se o conceito de torneio se tornasse muito popular, então os estudantes poderiam abandonar os princípios básicos e praticar somente para as competições. (Nakayama, 1983, p. 38)

Por que tanta preocupação com os princípios do karate? A descrição do processo de aprendizagem responde parcialmente a essa questão quando indica o objetivo de transcendências. Preliminarmente à luta de fato, é preciso o 
desapego a aspectos que devem tornar-se como que instintivos, como é corrente dizer-se entre os praticantes acerca das habilidades assimiladas, que passam a atuar de modo reflexo, ou seja, ganham autonomia e se caracterizam fenomenologicamente como as habitualidades do corpopróprio mencionadas por Husserl (2002). Incorporados, tais aspectos liberam a consciência para posicionar-se no fluxo do agora perceptivo.

O caminho que o zen pretende traçar é de esquecimento, esquecimento das atribuições que são feitas em torno do contato direto com a realidade última. Nesse percurso, atribuições morais, certo e errado, bem e mal, vão passo a passo deixando de fazer sentido. Esse é um percurso constante de esvaziamento para o alcance do âmago da realidade, onde fenecem conceitos e onde se pratica o ato puro. $\mathrm{O}$ ato puro, por ser a manifestação da verdadeira visão ${ }^{3}$, ocasionaria sempre o bem, pois essa seria a natureza do contato puro com a realidade. Este bem é desprovido de um saberse bem e, comumente, do orgulho proveniente de se praticar o bem. Nessa perspectiva, o orgulho é um atributo criado pelo homem, está muito distante da sua essência. O ato puro é um ato que se exige, é a verdade que, a partir do momento em que forem transcendidos os fatores que impedem seu alcance - ocasiona a retidão moral e ética. Funakoshi aponta alguns destes fatores de impedimento:

... a pessoa que segue o Caminho do karate deve esvaziar-se, livrando-se de todo egoísmo e ambição. (1988/ 1998, p. 25)

. . . o praticante de karate-do deve purificar-se do egoísmo e dos maus pensamentos, pois só uma mente pura pode compreender, sem distorção, o que recebe. (1935/1997, p. 4)

Suzuki faz descrição semelhante do Zen:

O Zen, não raro, compara a mente a um espelho livre de manchas. Ser simples, portanto, de acordo com o Zen, significa manter este espelho sempre brilhante e limpo, pronto a refletir pura e simplesmente o que dele se acercar. (1969/1993, p. 83)

Esta purificação que visa acessar a essência humana sintonizada à natureza é assim mencionada por Nakayama quando descreve o kara (de karate):

Este significado original era 'estar carente' ou 'necessitado' (ou também 'abandonado' ou 'esvaziado'), para chamar o indivíduo a escapar das regras e diferenças entre bem e mal, realidade e ilusão. Isto, de acordo com o budismo Mahayana, fortalece a ética individual no que diz respeito ao fato de que se uma pessoa não estiver presa a nada, ela naturalmente escolherá o bem sobre o mal. (1983, p. 62)

A concepção é de que estágios mais sofisticados devem refletir aquilo que está no princípio, a essência e origem da realidade, que deve ser referência para tudo, a todo momento. A variedade de possibilidades entre golpes, técnicas, estratégias e táticas deve ser direcionada para retornar ao princípio original que é o verdadeiro objetivo a que se presta toda e qualquer ação. A origem conceitual que define o karate é o kime ${ }^{4}$, sua essência técnica e transcendente - enquanto não tem forma ou objetivo pré-definido, embora demande determinada disposição voluntária - de onde derivam princípios que, sendo seguidos fielmente, levariam à retidão moral e espiritual.

. . . Se os princípios básicos estão corretos, não fará diferença o que o karateka estiver fazendo. Os princípios são os mesmos, e eles servem ao karateka bem o tempo todo, em qualquer circunstância (Nakayama, 1983, p. 92).

Desse modo, "nós simplesmente devemos manter em mente nossos propósitos fundamentais" (Nakayama, 1983, p. 90) que são as bases para o karate-do, pois "o karate serve para desenvolver uma filosofia, uma prática de vida" (p. 34). Como desenvolvimento de um modo de vida, o karate se volta sempre a seu fundamento, sua essência, algo a que o próprio karateka deve referir-se sempre. O kime conceituaria, na prática, um constante retorno à essência como representante legítimo da realidade última, de um retorno ao que é fundamental. Esse retorno faz do pensamento que reduz o corpo a corpo atlético, corpo máquina, corpo arma, corpo funcional, um pensamento que o amplia a corpo filósofo. É corpo filósofo na medida em que o pensamento, por si só, não se aproxima daquela atuação própria da "filosofia oriental" (Cheng, 1997), é preciso a participação efetiva do corpo e de sua experiência, já que é ali que a realidade inicia e finda seu sentido. Observe-se que não se trata de uma especulação acerca de um corpo empírico, este corpo filósofo questiona vivencialmente a vida e a morte, é um corpo que filosofa por via perceptivotranscendente - de acordo com a concepção budista - em direção à origem, podendo vir a ser, por fim, corpo totalidade. É o corpo que, em sua tensão inerente, ultrapassa o questionamento filosófico e se abre à afirmatividade que orienta a religiosidade, $\mathrm{o}$ abandono confiante à realidade $\mathrm{e}$ sua condição fundamental, o que se expressa pela imagem budista de "tocar o nirvana com o corpo" (Keown, 1999, p.96).

\section{Esvaziamento e Psiquismo}

A consciência - com suas possibilidades racionais especulativas - e a emoção - com seus movimentos afetivos participam desse processo transcendente de retorno à fonte original que sustentaria a realidade e que sustentaria também os artifícios manipulados pelo homem e que o dis-
${ }^{3}$ Manifestação única daquilo que se apresentou como o contato com a "realidade última" que é aquilo que se apresenta no esvaziamento. Portanto, a "verdadeira visão" só pode estar vinculada ao caminho do esvaziamento e não fixamente àquilo que é encontrado, pois aquilo que é encontrado nunca é igual, transcende a cada instante, embora seja um estado de espírito que se possa definir.

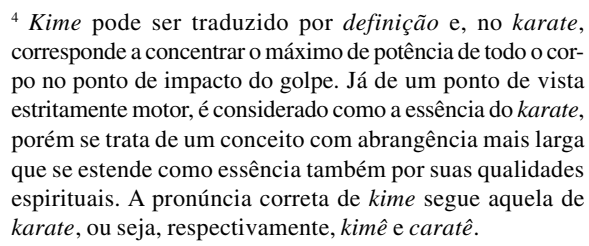

${ }^{4}$ Kime pode ser traduzido por definição e, no karate, corresponde a concentrar o máximo de potência de todo o corpo no ponto de impacto do golpe. Já de um ponto de vista estritamente motor, é considerado como a essência do karate, porém se trata de um conceito com abrangência mais larga que se estende como essência também por suas qualidades espirituais. A pronúncia correta de kime segue aquela de karate, ou seja, respectivamente, kimê e caratê. 
tanciariam desta fonte, iludindo-o e causando o sofrimento apregoado pelo budismo. A participação da consciência e da emoção tem aqui uma orientação bem definida e coerente com o sentido interno dessa espiritualidade. Vista do exterior, a participação e definição dessas duas categorias na espiritualidade e pensamento orientais são facilmente mal interpretadas como sendo irracionais e afetivamente tolhidas, enquanto, na verdade, primam por e valem-se de um enraizamento da razão e de uma harmonização dos afetos. Não a reflexividade ocidental moderna, mas os traços de um ideal de circularidade energética e de unificação da exterioridade e da interioridade, com raízes que se definem no confucionismo, no budismo e no taoísmo, difundindo-se no pensamento chinês e no mundo sino-aculturado, é que podem, através do direcionamento da força física do corpo para realizar o kime, conjugar uma orientação que se estende para a razão e para a emoção. Esta extensão é contemporaneamente contenção da razão e da emoção àquela tensão necessária para realização do kime, tensão avessa a racionalizações e euforias. O kime não direciona simplesmente um recorte do homem entendido como força e coordenação muscular, o kime direciona a energia $(K i)$, responsável pelo homem e universo inteiros.

Mas como não enxergar contradição entre um ideal de retorno ao princípio original - à verdade que em última instância implica em esquecimento das atribuições racionais feitas a respeito da realidade - e o processo racional, metódico e gradual do treinamento de karate? A não contradição reside no fato de que a razão usada para desenvolver esses métodos, como também a razão usada para argumentar sentidos, não é uma razão platonicamente deificada, mas um instrumento secundário e transicional para edificar uma obra de fidelidade aos princípios básicos da experiência humana e retorno à origem, retorno que é a prioridade desta concepção.

É certo que, no plano de intersecção Ocidente/Oriente em que se encontra o karate moderno, esse pensamento tem suas soluções no vértice oriental, por contraste e oposição a uma extrema ocidentalização no molde de um processo civilizatório do qual participa o conceito esportivo. Uma primeira menção a este respeito encontra-se em Barreira e Massimi (2006) onde são indicadas relações entre aspectos históricos do karate e a leitura de Norbert Elias que associa o processo civilizatório moderno com o surgimento do esporte moderno. Nakayama defende a solução através do enlace àquele vértice oriental e ao mesmo tempo promove o karate esportivo, sob o risco e a pena de haver uma degradação da tradição, da visão de mundo e da concepção de homem inerente ao karate-do, ao karate como Caminho. Na tentativa de conciliação, vê-se que, tanto a centralidade do esporte, como a centralidade da razão no vértice ocidental da prática de exercícios físicos, são manifestadamente marginalizados e postos a serviço de um homem visto, pensado e vivido integralmente. Entretanto, é preciso apontar, a esportivização promoveu, voluntária ou involuntariamente, modificações profundas no karate que serão abordadas em outro estudo.
Assim, o contato com a essência humana não desconsidera o uso da razão. Agir natural e espontaneamente, como quer o ideal do desprendimento e esvaziamento budista, não é tampouco se deixar levar pelas emoções, como o faria o principiante em artes marciais ao lutar seus primeiros combates: dominado por emoções, via de regra, medo ou fúria. O karate esportivo pode contribuir para a obtenção de um controle sobre as emoções que, enquanto relacionadas ao desejo, precisam passar por um processo de purificação, que se realiza por um direcionamento das vivências subjacentes ao momento do combate, entre elas as vivências racionais. Esse controle das vivências emocionais e racionais seria tão mais eficiente, na noção de autodomínio de que se acerca, quanto mais coordenada com a diluição dos desejos próprios do eu (ego) e da afirmação de sua identidade construída no distanciamento individual da fonte original, a ação fundida à intencionalidade, à consciência. Pela perspectiva budista, emoção e razão, prendendo-se aos desejos do $e u$, dominarão este homem que tem como alternativa ideal implícita, no karate-do, apegar seu desejo a um desejo que pode ser considerado cósmico e que está inscrito nos princípios fundamentais do karate. Pode-se entender que este é o motivo tácito do alerta de Nakayama de que "se é para realizar competições de karate, que sejam realizadas em condições apropriadas e no espírito adequado" (Nakayama, 1977/1996, p. 10). Por espírito adequado entende-se um estágio relativamente avançado de controle técnico e emocional. Nakayama continua, considerando que "o desejo de vencer uma disputa é contraproducente, uma vez que leva a uma falta de seriedade no aprendizado dos fundamentos" (p. 10). Isto deixa transparecer a preocupação de que o desejo e as emoções vinculadas a ele se sobreponham aos fundamentos, aos princípios essenciais que têm em sua busca o auxílio do método racional de aprendizagem. Esta sobreposição seria como "uma exibição selvagem de força e vigor numa disputa, que é algo totalmente indesejável" (p. 10).

Portanto, o percurso seguido ao controle de mente e corpo, é um percurso que implica as já insistentemente referidas transcendências. No plano esportivo, contudo, essa dinâmica de transcendências, implícita no ideal do karate$d o$, fica comprometida. No esporte, trata-se de uma dimensão de transcendências que se limita a assimilar e tornar natural o autocontrole técnico e emocional que, pelo argumento de Nakayama, só pode se dar se houver compromisso com os fundamentos que são contemporaneamente técnicos e morais: o kime, o respeito à idéia de ikken hissatsu (matar com um golpe) que incide na necessidade de reconhecimento da morte imaginária, ou seja, da vitória e da derrota, e o sun-dome (parar o golpe antes de se atingir o alvo) que preserva a integridade física do adversário. Por isso, o plano esportivo fica aberto a concepções diferentes de autocontrole, concernentes ao respeito dessas regras esportivas fundamentais. Havendo domínio sobre as técnicas, emoções e razão, pode haver supostamente o retorno ao estágio do principiante em âmbito esportivo e, mais amplamente, em âmbito humano. 
O estágio do principiante é, por paradoxal que soe, um estado avançado do aprendizado de uma técnica, que passa a se manifestar não mais tecnicamente, mas artisticamente. Há o retorno da espontaneidade do leigo que, sem qualquer conhecimento técnico a respeito de uma especialidade qualquer, ao se propor a atuar em algo relativo a essa especialidade, age desprendido dos referenciais técnicos que tomam a atenção e o cuidado dos iniciados. Retornar a esse estágio e permanecer nele significa tornar-se mestre na concepção do budismo zen. A espontaneidade do principiante é, para o zen, um retorno à ingenuidade infantil (Suzuki, 1953/1975). Porém esse retorno, ou a ingenuidade infantil, se manifesta na arte sob novas condições (Suzuki, 1960/s.d.). No caso do karateka, são condições relacionadas às habilidades técnicas que se manifestarão em seus gestos, agora com uma espontaneidade e harmonia artísticas. O estágio do principiante, não perdurando apenas como um estado, mas como condição estável, como maestria artística, manifesta em seu gesto uma ação que se confunde com retidão moral e profundidade espiritual. Se é possível associar à ação corpórea qualidades morais e espirituais, isso se dá, entre os fatores internos descritos na concepção, porque o gesto é proveniente de uma estratificação cultural que se acumulou sobre o fato de que "os conceitos e idéias, as línguas e os modos de pensar orientais foram modelados, até certo ponto, por sua conexão íntima com as habilidades físicas" (Hironishi, 1975/1994, p. 8). Já o esporte insere-se em uma concepção de mundo ocidentalizada, que cinde mais e mais ação e arte, de moral e de espiritualidade. Talvez em âmbito esportivo nem sempre seja conveniente tratar a ação, por mais perfeita, livre e espontânea que seja, por própria do estágio do principiante; já que na praxe ocidental há hegemonicamente cisão conceitual entre gesto e moral, entre corpo e espírito. Mais do que isso, o esporte ocidental e suas intenções íntimas se isentam de concepções espirituais integrativas, sendo definitivamente laicizado.

\section{Esvaziamento e Combate}

O kime é essência técnica do karate, frisando-se que ele é exigido desde o início da aprendizagem até o mais alto grau de maestria. Sua tradução é literalmente "definição", contudo, tecnicamente, deve ser compreendido como a aplicação rápida e explosiva de um golpe em que a força de todo o corpo se concentra no impacto. Trata-se de um conceito que é relacionado diretamente ao ikken hissatsu (matar com um só golpe) que provém das lutas de vida ou morte no Japão feudal. Estas lutas, segundo Nakayama, originaram a filosofia heijo shin koro michi que dita uma atitude em todo momento da vida equivalente à do momento da morte. Havendo a alta expectativa entre os samurais de morrer dignamente, procurava-se manter a dignidade em todo instante da vida, pois isto daria prontidão para e garantia de uma morte nobre. Como o conceito de kime vincula-se à necessidade de matar com um único golpe, o kime remete imediatamente à morte (Barreira \& Massimi, 2006). Essa remissão à necessidade do homem de manter-se vivo no calor do combate, frente a um adver- sário que com ele disputa a sobrevivência, expande-se e sofistica-se. Ou seja, a tradição que movimenta o karate não se reduz à necessidade de sobrevivência. Como já exposto, Nakayama toma a filosofia (heijo shin koro michi) que nasce destas circunstâncias bélicas como o pilar da cultura nipônica. O sentimento nutrido em torno dessa tensa relação entre a vida e morte não se coibiria a edificar práticas guerreiras, mas seria o móbile em torno do qual se configuram o caráter e a espiritualidade japoneses. Essa tensão, longe de significar uma constrição humana e cultural paralisada diante da face da morte, deu vazão a uma forte espiritualidade e valorização da vida, através da presentificação de seus mais profundos sentidos que, no limite, são expressos nos mais simples gestos. Essa espiritualidade penetra também as práticas guerreiras e se expande mesmo quando circunstâncias históricas poderiam influenciá-las contrariamente. É o que se pode salientar através desse trecho do prefácio de Edwin O. Reischauer ${ }^{5}$ para o romance histórico Musashi de Eiji Yoshikawa:

. . . importante transição no Japão dos tempos de Musashi ocorreu no setor de armamentos. Na segunda metade do século XVI, mosquetes - recém introduzidos pelos portugueses - haviam se transformado em armas decisivas nos campos de batalha, mas numa terra pacificada, os samurais podiam voltar as costas às repugnantes armas de fogo e reatar seu tradicional affaire com a espada. Escolas de esgrima floresceram. No entanto, na medida em que diminuíam as oportunidades de usar espadas em combates reais, habilidades marciais transformavam-se gradativamente em artes marciais, estas passaram a dar uma importância cada vez maior ao autocontrole e às qualidades edificantes da esgrima, preferindo-as a uma eficácia bélica não testada. Criou-se uma mística inteira em torno da espada, muito mais filosofia do que técnica de combate. (1999, p. 14)

Herdeiro de uma conjuntura histórica de traços semelhantes, ocorrida em Okinawa e influenciado no começo do século XX pela tradição do budô japonês, o karate-do tem como objetivo o aperfeiçoamento do caráter. A respeito desta mesma transição histórica, que pode ser considerada amplificadora de perspectiva para as artes de combate japonesas, tem-se o relato de Eugen Herrigel pertinente para a presente análise. Em sua obra $A$ arte cavalheiresca do arqueiro zen, em que aborda seu aprendizado na arte do arqueiro da tradição japonesa, Herrigel contextualiza a função zen da arte, oferecendo as considerações reveladoras a seguir:

É preciso lembrar que, depois de perdida toda a utilidade nos combates e competições, o espírito dessa arte se manifestou de maneira nítida e espontânea. Assim é um erro afirmar-se que esse espírito tenha surgido recentemente, uma vez que sempre foi inerente ao tiro com arco, desde os seus primórdios. Mas sua técnica (depois de ter perdido qualquer importância para o

${ }^{5}$ Reischauer fora embaixador americano no Japão e professor na Universidade de Harvard. 
combate) não se converteu num passatempo ameno, sem sentido e seriedade. A Doutrina Magna do tiro com arco nos diz outra coisa. Segundo ela, desde os seus primórdios, trata-se de uma questão de vida e morte, na medida em que é uma luta do arqueiro consigo mesmo. Essa forma de luta não é uma medíocre contrafacção, mas sim o que inspira e sustenta toda a luta contra o mundo exterior e, talvez, contra um adversário de carne e osso. (1975/1995, p. 17)

Mantém-se o espírito dessas artes de combate, a luta de vida e morte, contudo há uma mudança de perspectiva que permite que a manifestação desse espírito sirva ao objetivo presente no zen. Nesse sentido, a prática do karate-do se volta como uma "luta interior" em que o kime, pensado como transcendente, é essencial, pois remete originalmente à proteção da vida diante da morte. Herrigel sugere que a origem de qualquer necessidade de luta exterior possa ser solucionada a partir da luta consigo mesmo, sendo aí a arena em que se devem travar os combates humanos. Dar a dimensão de vida e morte aos embates consigo mesmo significa trazer a responsabilidade ao homem pela origem de todas as suas ações decisivas, incluindo as ações geradoras e gerenciadoras de conflitos. Apesar de se encontrar nesta compreensão argumentos dualistas e que, pela própria origem e formação alemã de Herrigel, remetem mesmo a certo idealismo, pode-se também supô-la como uma compreensão relevante na história das idéias, até mesmo por suas influências enquanto categorias assumidas pelo diálogo intercultural acerca da espiritualidade japonesa que, então, se intensificava. Sem que se atenha aos importantes exames críticos da formação destes argumentos (para tanto veja-se Shoji, 2001), é relevante notar que, de fato, mesmo para um intérprete das artes marciais japonesas contemporâneo e fenomenologicamente atento, como Kenji Tokitsu, uma periodização do desenvolvimento destas artes enxerga no século XIX um florescimento que inspira a busca por uma harmonização da agressividade ofensiva, em que "a realização ideal do budô é um combate onde a energia agressiva é perfeitamente equilibrada pelo componente oposto, a harmonia" (Tokitsu, 1998, p. 18). Há, portanto, uma concepção de aperfeiçoamento correspondente a um processo de interiorização que, no entanto, não se dá fora ou independentemente da relação combativa ou do "mundo exterior".

Mantendo a noção de combate consigo mesmo, sem, contudo, assumi-la como destacada do combate propriamente dito, ao contrário, encontrando-a justamente na real ou potencial relação combativa, pode-se ler o modo como Funakoshi dirige uma advertência a respeito da intenção de fazer uso do karate em lutas:

. . . a partir do momento em que o karate entra em cena, tudo se transforma em uma questão de vida e morte. E como podemos nos permitir entrar em confrontos de vida e morte freqüentemente tendo tão poucos anos de vida sobre a terra? (1975/1994, p. 103)

No karate-do, podem ser localizadas influências que norteariam duas principais vertentes, puristas quanto à raiz oriental, ao combate consigo mesmo. Pela tradição confu- ciana, o combate valer-se-á de uma auto-argüição em torno da justiça de uma dada situação, ou seja, de um autoexame racional na procura da solução justa. $\mathrm{O}$ confuciano Mêncio (372-289 a.C.) ilustra um caso para auto-argüição:

Há um homem que me trata de modo perverso e irrazoável. Neste caso o homem superior dirá a si mesmo: 'Deve haver-me faltado benevolência. Deve haver-me faltado correção. Como pode ter acontecido isso?' Examina-se a si mesmo e é acentuadamente benévolo. Esquadrinha o seu íntimo, e é especialmente respeitoso à correção. A perversidade e a conduta irrazoável do outro, no entanto, continuam a existir. $\mathrm{O}$ homem superior voltará a dizer-se: 'Não terei feito tudo o que podia?'

Volta sobre si mesmo e continua a fazer tudo o que pode, mas apesar disso repetem-se a perversidade e a conduta irrazoável do outro. À vista disso, o homem superior diz: 'Evidentemente, este é um homem completamente perdido! Pois que se conduz desse modo, que diferença existe entre ele e um animal? Por que hei de contender com um animal?' (Doeblin, 1940, p. 85-86)

A orientação do pensamento confuciano é a de que as ações, contidas nestas palavras, destinem-se a consequiências virtuosas. Por sua vez, a origem das virtudes é própria da natureza e é o auto-exame que deve auxiliar o esclarecimento desta origem, reforçando sua abrangência.

Funakoshi se vale desse procedimento, como se lê em suas máximas para o praticante que reporta àquela busca de equilíbrio como um processo de interiorização:

Se a introspecção me revela como injusto, então não importa o quão baixo for o meu oponente: não é verdade que eu terei medo? E se a introspecção me revela como justo, então, eu enfrentarei ainda que mil ou dez mil homens. (1935/1997, p. 273)

No interior de uma visão cosmológica que prevê o equilíbrio do homem como um equilíbrio com a natureza, o céu e a terra, as virtudes e a moralidade são tanto mais verdadeiras quanto mais coladas à fluidez da natureza (conforme a noção de mutação taoísta) e à tensão vivencial, muito antes de uma conclusão categorial da moral intelectualmente construída. $\mathrm{O}$ exercício racional examina a fundo a intenção e se esforça em mantê-la fiel à tensão proveniente da natureza contemporaneamente cósmica e humana.

A outra influência é de origem budista e um tanto quanto incompatível em relação à confuciana. Desde o início da expansão budista na China (I d.C.) até o "renascimento" confuciano, entre os séculos X e XIII, budismo e confucionismo eram linhas paradoxais e conflituosas. $O$ renascimento confuciano, modernamente chamado neoconfucionismo, obteve relativo sucesso em aproximar as três grandes tradições - confucionismo, budismo e taoísmo - as quais, a despeito das incontáveis diferenças entre si (sobretudo naquilo que dizia respeito à orientação de conduta prática no cotidiano), passaram a ser entendidas como tendo a mesma origem, o mesmo fundamento último para a natureza da realidade e para a natureza humana, o que fortalecia uma visão de mundo antropocósmica (Cheng, 1997). 
O budismo zen norteia uma qualidade mais espiritualista do que moralista para a atitude desejável ${ }^{6}$. No esvaziamento, está a retirada da dinâmica racional, diga-se, de qualquer auto-argüição intelectual na assunção de uma postura diante da realidade. No karate-do, surgem inseridas ambas as vertentes, a de cunho confuciano e a zen. A mesma ontologia ${ }^{7}$ vem à tona através dessa tensão entre vida e morte, não reduzida a um dualismo, mas compreendida a partir da dinâmica circular do $k i$ (energia universal), que também se manifesta elementarmente entre inspiração e expiração, contração e expansão.

Considerando que essa busca do esvaziamento se evidencia, por exemplo, na prática contínua de kata no karate - também com os disparos com o arco no kyudo - e que se inicia quando há superação da reflexão em favor da contemplação, a retomada dos fundamentos zen budistas faz com que se conclua que o chamado à origem interior da ação não seja um chamado a um desvinculamento com o mundo exterior. Esse chamado é necessário justamente para o alcance da unidade entre o homem e o Universo, sendo que o alcance dessa unidade é dinâmico e parte de uma inspiração natural em acordá-los. Nessa vivência de unidade, a ação dispara a si própria, quando está madura. Nesse momento, não há mais distinção entre sujeito e objeto, mundo exterior e mundo interior. O caminho do Meio, de inspiração confuciana, que não se refere a uma precaução em manter-se num posto eqüidistante entre dois extremos, é equivalente a essa vivência da ação por maturação, que ocorre no auge da eficácia ritual e se manifesta como pólo de atração ao que há de melhor e inato no homem, sua natureza (Cheng, 1997, p. 41-42). Finalmente, existe a imagem do tiro que atinge o próprio agente de seu disparo, pois, de tão revelador, este momento rompe pré-concepções sobre a realidade, rompe com tudo o que parecia importante ao iniciante e, de certa forma, destrói um mundo ao assassinar as ilusões intelectuais que o mantinham, apresentando a ele a realidade verdadeira. E qual realidade é esta? Não é a realidade intelectualmente mediada, afinal Suzuki alerta que "o Zen sempre desejou captar o fato central da vida, o qual nunca poderá ser traduzido à mesa dissecadora do intelecto" (1969/1993, p. 73).

Para a perspectiva zen, em última instância, o fim desse embate interior, o fim dessa concepção dualista geradora das dúvidas da humanidade, findaria também os combates exteriores, as dúvidas que não podem ser respondidas pela razão, que é a própria produtora das dúvidas, dúvidas que causam a ansiedade e o sofrimento.

Logo que houver sinais de elaboração, um homem se escraviza, não é mais um ser livre. Não estás vivendo como deves viver, estás sofrendo a tirania das circunstâncias, sentindo uma espécie de restrição e perdendo a

${ }^{6}$ De fato, pode-se associar mais intensamente, embora não exclusivamente, a moralidade manifesta no karate-do com o confucionismo e sua espiritualidade manifesta com o budismo zen. Ver Barreira e Massimi (2002, 2003). tua independência. O Zen trata de preservar a tua vitalidade, a liberdade nativa, e acima de tudo a integridade do teu ser. Em outras palavras, o Zen quer viver de dentro. Não ser preso a regras e sim criar as próprias regras. (Suzuki, 1969/1993, p. 87)

Está-se diante de uma unidade pré-conceitual: é uma experiência pré-lógica sobre a qual se configuram conseqüências morais, afetivo-racionais e experiências religiosas que encarnam justamente aquilo que foi perpetuado pela tradição e pela reatualização vivencial como a essência humano-cosmológica, o re-ligamento.

\section{Conclusão}

A tomada do esvaziamento como o fio condutor destas análises encontra suas razões no próprio interior do karate. A multiplicidade de incidências que tem essa dinâmica do vazio - aprendizagem, moral, psiquismo, combate - poderia sugerir que se trata de um conceito tão abrangente que dispensável. No entanto, a abrangência do esvaziamento deve ser compreendida justamente como a garantia de que há um princípio e uma finalidade indispensáveis, tanto mais por ser menos um conceito do que uma dinâmica. O esvaziamento é uma experiência que, como princípio e finalidade, se manifesta efetivamente, por paradoxal que seja, de modo involuntário. O desejar esvaziar-se só permite o esvaziamento pleno quando se ausenta. Nesse sentido, é importante identificar a infinidade de dosagens possíveis para esta dinâmica. Pode tratar-se tanto de um esvaziamento intelectual e moral, prontidão voluntária à recepção da alteridade, como de um esvaziamento plenamente espiritual, abertura total que, no limite, dê acesso à experiência mística. Do ponto de vista cultural, é relevante destacar que, ao longo da história, o esvaziamento tende a se voltar à relação com a natureza muito mais do que à relação com a alteridade humana. Da relação combativa, homem a homem, entretanto, emerge uma considerável necessidade de abertura ao outro, conforme analisado em Barreira (2006). As práticas individuais, contudo, mais valorizadas do que o treinamento a dois no karate tradicional de Okinawa, indicam a tendência a uma abertura e relação homem/natureza. Portanto, não se trata de um voluntarismo, mas de uma prática e um intenso combate subtrativo: efetivação da exclusão de conteúdos que se impõem como mediação e obstáculo entre sujeito e objeto, homem e absoluto.

$\mathrm{Na}$ concepção do mundo sino-aculturado, a eliminação do obstáculo não significa o fim da dualidade, mas sua conjunção promovendo uma experiência ternária, contato com o vazio original com o qual se deve acordar. É o homem que pode e deve fazer esta experiência a qual, conforme a especulação cosmológica chinesa, religaria Céu e Terra aperfeiçoando a obra cósmica (Cheng, 1997). O homem não apenas está no meio como deve também agir em acordo a isso, situando-se pelo caminho do meio que é "um pólo do qual a atração nos leva para o alto, criando e mantendo em toda situação da vida humana uma 
tensão que nos faz aspirar sempre à melhor parte daquilo que nasce entre nós" (p. 42).

A espiritualidade, portanto, como o sentido que permite compreender o acesso a tal pólo de atração, está naquilo que subjaz à essência do karate, o kime. A definição do gesto (kime) sintetiza o princípio, o produto, e a filosofia corporal constituída no karate e positivamente garantida pela experiência espiritual do esvaziamento.

\section{Referências}

Ales Bello, A. (2003). Il simbolo nell'esperienza sacrale-religiosa: un'analisi fenomenologica. Memorandum, 5, 134-147. Retrieved December 8, 2003, from http://www.fafich.ufmg.br/ $\sim$ memorandum/artigos05/alesbello02.htm.

Barreira, C. R. A. (2006). A alteridade subtraída: o outro no esvaziamento do karate e na redução fenomenológica. Mnemosine, 2(2), 106-118. Retrieved July 10, 2007, from http:/ /www.cliopsyche.cjb.net/mnemo/index.php/mnemo/article/ viewFile/109/180

Barreira, C. R. A. \& Massimi, M. (2002). A moralidade e a atitude mental no karate-do no pensamento de Gichin Funakoshi. Memorandum, 2, 39-54. Retrieved May 31, 2002, from http:// www.fafich.ufmg.br/ memorandum/artigo02/barreira01.htm.

Barreira, C. R. A. \& Massimi, M. (2003). As idéias psicopedagógicas e a espiritualidade no karate-do segundo a obra de Gichin Funakoshi. Psicologia Reflexão e Crítica, 2(16), 379388.

Barreira, C. R. A. \& Massimi, M. (2006). O caminho espiritual do corpo: A dinâmica psíquica no karate-do shotokan. Memorandum, 11, 85-101. Retrieved July 10, 2007, from http:/ / w w w.fafich.ufmg.br/ m e morandum/a 11 / barreiramassimi03.htm.

Cheng, A. (1997). Histoire de la pensée chinoise. Paris: Seuil.

Coelho, A. G., Jr. \& Mahfoud, M. (2006). A relação pessoa-comunidade na obra de Edith Stein. Memorandum, 11, 08-27. Retrieved July 18, 2007, from http://www.fafich.ufmg.br/ $\sim$ memorandum/a11/coelhomahfoud01.pdf

Doeblin, A. (1940). O pensamento vivo de Confúcio (O. G. Pinheiro, Trad.). São Paulo, SP: Martins.

Funakoshi, G. (1994). Karate-do: O meu modo de vida (E. L. Calloni, Trad.). São Paulo, SP: Cultrix. (Original publicado em 1975)

Funakoshi, G. (1997). Karate-do Kyohan: The master text (T. Oshima, Trad.). Tokyo: Kodansha International. (Original publicado em 1935)

Funakoshi, G. (1998). Karate-do Nyumon: Texto introdutório do Mestre (E. L. Calloni, Trad.). São Paulo, SP: Cultrix. (Original publicado em 1988)

Gardini, W. (1989). Japon entre mitos y robots: el shinto. Buenos Aires, Argentina: Sekai.

Habersetzer, G. \& Habersetzer, R. (2000). Encyclopedie des arts martiaux de l'extreme Orient: technique, historique, biographique et culturelle. Saint-Nabor, France: Amphora.

Herrigel, E. (1993). O caminho zen (Y. S. de Toledo \& Z. H. Schild, Trads.). São Paulo, SP: Pensamento. (Original publicado em 1958)

Herrigel, E. (1995). A arte cavalheiresca do arqueiro zen (J. C. Ismael, Trad.). São Paulo, SP: Pensamento. (Original publicado em 1975)

Hironishi, G. (1994). Apresentação (E. L. Calloni, Trad.). In G. Funakoshi (1994). Karate-do: O meu modo de vida. São Paulo, SP: Cultrix. (Original publicado em 1975)
Husserl, E. (1992). Conferências de Paris (A. Fidalgo \& A. Mourão, Trads.). Lisboa, Portugal: Edições 70.

Husserl, E. (2002). La crisi delle scienze europee e la fenomenologia trascendentale (E. Filippini, Trad.). Milão: Saggiatore.

Keown, D. (1999). Buddhismo (M. Maglietti, Trad.). Turim: Einaudi.

Massimi, M. (1998). A história das idéias psicológicas: Uma viagem no tempo rumo aos novos mundos. In G. Romanelli \& Z . M. Biasoli-Alves (Eds.), Diálogos metodológicos sobre prática de pesquisa (pp. 11-30). Ribeirão Preto, SP: Legis Summa.

Massimi, M., Campos, R. H., \& Brozek, J. (1996). Historiografia da Psicologia: Métodos. In R. H. Campos (Ed.), História da psicologia: Pesquisa, formação e ensino: Vol. 15. Coletâneas da ANPEPP (pp. 29-56). São Paulo, SP: Associação Nacional de Pesquisa e Pós-Graduação em Psicologia.

Nakayama, M. (1983). Conversations. In R. G. Hassel. Conversations with de Master: Masatoshi Nakayama. Philadelphia, PA: International Shotokan Karate Federation.

Nakayama, M. (1996). O melhor do karate 1: Visão abrangente, práticas (C. Fischer, Trad.). São Paulo, SP: Cultrix. (Original publicado em 1977)

Nakayama, M. (1998). O melhor do karate 3: Kumite 1 (D. C. R. Delela \& S. N. Ferreira, Trads.). São Paulo, SP: Cultrix. (Original publicado em 1978)

Reischauer, E.O. (1999). Prefácio. Em Yoshikawa, E. (1999). Musashi. (L. Gotoda, Trad.). São Paulo: Estação Liberdade.

Shoji, Y. (2001). The Myth of Zen in the Art of Archery. Japan Journal of Religious Studies, 28(1-2), 1-30. Retrieved July 10, 2007, from http://www.nanzan-u.ac.jp/SHUBUNKEN/ publications/jjrs/pdf/586.pdf

Suzuki, D. T. (1936). Buddhist philosophy and its effects on the life and thought of Japanese People. Tokyo: Kokusai Bunka Shinkokai.

Suzuki, D. T. (1975). Introdução (J. C. Ismael, Trad.). In E. Herrigel (Ed.), A arte cavalheiresca do arqueiro zen. São Paulo, SP: Pensamento. (Original publicado em 1953)

Suzuki, D. T. (s.d.). Conferências sobre zen-budismo (O. M. Cajado, Trad.). In E. Froom (Ed.), Zen-budismo e psicanálise. São Paulo, SP: Cultrix. (Original publicado em 1960)

Suzuki, D. T. (1993). Introdução ao zen-budismo (M. N. de Azevedo, Trad.). São Paulo, SP: Pensamento. (Original publicado em 1969)

Tokitsu, K. (1998). Miyamoto Musashi: maître de sabre japonais du XVIIe siècle, l'homme et l'ouvre, mythe et réalité. MéolansRevel: DésIris. 